\title{
Research on Multi-dimensional Energy Efficiency Assessment Technology of RIES
}

\author{
Kuihua Wu ${ }^{1, a}$, Zhijie Zheng ${ }^{1}$, Lujie Qi ${ }^{1}$, Rong Liang ${ }^{1}$ and Bo Yang ${ }^{1}$ \\ ${ }^{1}$ State Grid Shandong Electric Power Company, Economic \& Technology Research Institute, China
}

\begin{abstract}
At present, there is a lack of regional comprehensive energy multi-dimensional evaluation system and calculation of different quality energy in the energy efficiency evaluation of regional integrated energy system. Based on this, this article carries out research on multi-dimensional energy efficiency evaluation index system and evaluation methods. First, this article form quantifiable evaluation indicators from the aspects of energy supply subsystem energy efficiency, energy conversion subsystem energy efficiency, grid energy efficiency, economic benefits and social benefits, and clarify the calculation methods of each evaluation indicator. Then this article calculate the indicator combination weight. Finally, a multi-dimensional energy efficiency assessment method for a regional integrated energy system is proposed, and an example is used to prove the effectiveness of the method.
\end{abstract}

\section{Introduction}

As an important carrier of the energy internet, the regional integrated energy system is the frontier for studying the internal operation mechanism of different energy sources and promoting advanced energy technologies[1-4]. Scientific and reasonable energy efficiency assessment method is extremely important for the healthy development of regional integrated energy system. In the research of multi-dimensional energy efficiency assessment technology for regional integrated energy system, the following problems still exist:

1)Establish a comprehensive multi-dimensional evaluation index system for regional comprehensive energy.

The multi-dimensional energy efficiency evaluation index of the integrated energy system is an important basis for system planning, design and regulation and optimization. A reasonable evaluation index structure is set up to integrate the five dimensions of energy supply system, energy conversion system, power transmission process, system economy, and environmental evaluation. Taking these into account will help to assist the better planning and operation of the integrated energy system.

2) The relationship between "quality" and "quantity" of energy should be fully considered in the assessment.

In the integrated energy system, the conversion process between different energy sources has the 'quantity' conservation and the 'quality' difference. Traditional energy efficiency calculations usually simply superimpose the energy of different qualities, which can only analyze the conservation of 'quantity', but lack of analysis of the difference of 'quality' and cannot scientifically characterize the degree of energy utilization. Therefore, it is necessary to convert different energy sources to the same energy level to measure the grade difference.

Under this background, the multi-dimensional energy efficiency evaluation index system and evaluation method are studied in this paper.

\section{Multi-dimensional energy efficiency evaluation index system of regional integrated energy system}

\subsection{Construction principles of indicator system}

In order to ensure the scientific rationality of the comprehensive energy efficiency evaluation results, the principles and directions of the evaluation indexes are determined according to the evaluation purpose and data collection conditions.

On the basis of the above principles, the evaluation index system is established by using the hierarchical analysis model. The hierarchical analysis model is divided into three layers, namely the target layer, the criterion layer and the scheme layer. The target layer is integrated energy efficiency. Energy efficiency of energy supply subsystems, energy efficiency of energy conversion subsystems, energy efficiency of the grid, economic benefits and social benefits as the criterion layer, and the scheme layer is a variety of energy efficiency indicators.

\subsection{Composition and architecture of indicator system}

This paper adopted the criterion layer evaluation index by the power subsystem indicators of energy efficiency, energy conversion system indicators of energy efficiency, 
power grid energy efficiency indexes and economic indexes, social benefit indexes of five modules[5].

In the energy efficiency module of the energy supply subsystem, consider gas supply, power supply, heating, and cooling subsystems, including their respective energy systems and power trains. The power system includes the power transmission link, which mainly takes into account the energy consumed by the power equipment in the power transmission process. In the energy efficiency module of the energy conversion subsystem, the conversion process between electric/thermal, gas/heat, gas/electricity, electricity/cold, heat/cold. Electrical energy is also lost during transmission, so the energy efficiency of the grid frame also needs to be taken into account. In the economic sub-module, the comprehensive cost method is adopted to reflect the economic level of the integrated energy system by the initial investment cost, operation maintenance cost and scrap cost index. In the Social Benefits submodule, climate change indicators and pollutant emission indicators are used to evaluate the environmental benefits of the benchmark system due to the replacement application of renewable energy and the efficient use of multi-energy synergies[6]. The establishment of an evaluation indicator system is as follows.

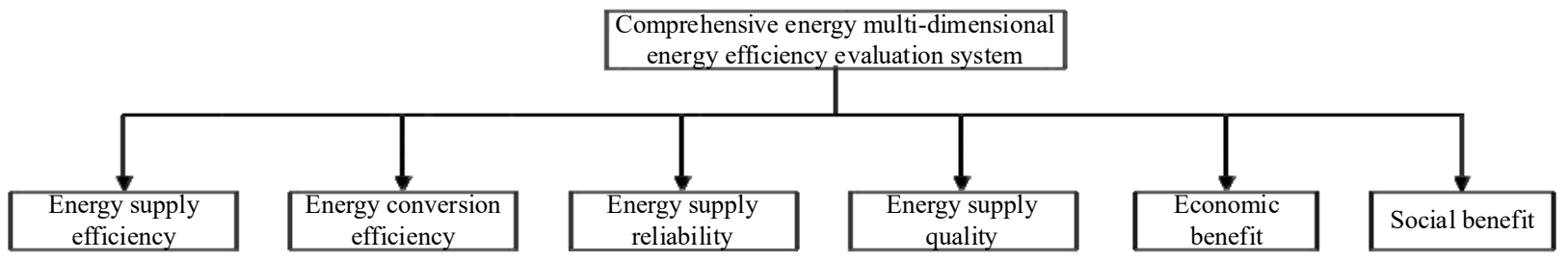

Fig1. Integrated energy multi-dimensional energy efficiency assessment metrics architecture.

Table 1. Comprehensive energy multi-dimensional energy efficiency assessment index system.

\begin{tabular}{|c|c|}
\hline Level indicators & The secondary indicators \\
\hline \multirow{4}{*}{ Energy supply efficiency } & Power supply efficiency \\
\hline & Cooling and heating network efficiency \\
\hline & Air supply efficiency \\
\hline & Power system efficiency \\
\hline \multirow{3}{*}{ Energy conversion efficiency } & Electricity to heat/cold energy conversion efficiency \\
\hline & Gas to electricity/thermal energy conversion efficiency \\
\hline & Heat to cold energy conversion efficiency \\
\hline \multirow{3}{*}{ Energy supply reliability } & Power supply reliability rate \\
\hline & Qualified rate of outlet pressure of gas pipeline network \\
\hline & Failure rate of cooling and heating equipment \\
\hline \multirow{4}{*}{ Energy supply quality } & $\begin{array}{l}\text { Qualified rate of harmonic content in medium and low voltage } \\
\text { station area }\end{array}$ \\
\hline & Voltage combination rate of medium and low voltage station area \\
\hline & Qualified rate of export natural gas quality \\
\hline & Qualified rate of cold and hot outlet temperature fluctuation \\
\hline \multirow{6}{*}{ Economic benefit } & Unit energy cost \\
\hline & Unit investment to increase energy supply \\
\hline & Unit investment reduces supply shutdown time \\
\hline & Financial net present value \\
\hline & Payback period \\
\hline & Financial internal rate of return \\
\hline \multirow{4}{*}{ Social benefit } & Renewable energy consumption rate \\
\hline & Proportion of renewable energy capacity \\
\hline & Annual $\mathrm{CO} 2$ emission reduction \\
\hline & Annual sulfur dioxide emissions reduction \\
\hline
\end{tabular}

\subsection{Normalized treatment of indicators}

There are different types of indicators, including ositive type and inverse type. In order to unify the types of indicators and evaluate the system more accurately, it is necessary to normalize the indicators. The normalization method is as follows.

1) Positive indicators

For positive indicators, which can be calculated by (1):

$$
a_{i j}=\frac{x_{i j}-m_{j}}{M_{j}-m_{j}}
$$


Among them, $M_{j}=\max \left\{x_{i j}\right\}, m_{j}=\min \left\{x_{i j}\right\}$. By processing the index, the value of the index will be $0 \leq$ $a_{i j} \leq 1$.

2)Inverse index

For reverse indicators, which can be calculated by (2):

$$
a_{i j}=\frac{M_{j}-x_{i j}}{M_{j}-m_{j}}
$$

Among them, $M_{j}=\max \left\{x_{i j}\right\}, m_{j}=\min \left\{x_{i j}\right\}$.By processing the index, the value of the index will be $0 \leq$ $a_{i j} \leq 1$.

\section{Weight analysis of multi-dimensional energy efficiency evaluation index of regional integrated energy system}

In the process of evaluation, it is inevitable to combine subjective and objective evaluation. The subjective weight was determined by AHP and the objective weight was determined by entropy weight method, and the final weight was determined by combining the two to get a more reasonable conclusion[7].

\subsection{Calculation method of subjective weight}

The basic principle of AHP method is as follows: First, the complex problem is divided into several levels, and the elements of the same level are judged in pairs according to the criteria of the elements of the previous level, and their importance is compared. Then calculate the weight of elements of each level. Finally, the optimal scheme is determined according to the combined weight and the principle of maximum weight[8]. The specific analytical steps of AHP method are as follows:

1) Establish a hierarchical model

Select the influencing factors according to the specific problem, and establish the appropriate level.

2) Determine the degree of relative importance After the establishment of the hierarchical model, it is necessary to judge the relative importance of each factor in each hierarchy $u_{i} . u_{j}(\mathrm{I}, \mathrm{j}=1,2,3 \ldots \mathrm{N})$ represents the factor, $u_{i j}$ said $u_{i}$ right $u_{j}$. The research refer to the Numbers 1-9 and their reciprocal as the scale.

Table 2. The cross-inverse scale.

\begin{tabular}{|c|c|}
\hline Scale & Meaning \\
\hline 1 & $\begin{array}{c}\text { Indicates that two factors are of equal importance } \\
\text { compared to each other }\end{array}$ \\
\hline 3 & $\begin{array}{c}\text { The former is slightly more important than the } \\
\text { latter }\end{array}$ \\
\hline 5 & $\begin{array}{c}\text { Indicates that the former is significantly more } \\
\text { important than the latter }\end{array}$ \\
\hline 7 & The former is more important than the latter \\
\hline 9 & The former is more important than the latter \\
\hline $\begin{array}{c}\text { The } \\
\text { bottom }\end{array}$ & $\begin{array}{c}\text { Represents the median value of the above } \\
\text { adjacent judgments }\end{array}$ \\
\hline
\end{tabular}

All values of relative importance will be obtained $u_{i j}$ Constitute the judgment matrix P, as (3).

$$
P=\left(\begin{array}{ccc}
u_{11} & \cdots & u_{1 n} \\
\vdots & \ddots & \vdots \\
u_{n 1} & \cdots & u_{n n}
\end{array}\right)
$$

3) Calculate the ranking of importance.

First, the maximum eigenvalue of the judgment matrix and the corresponding eigenvector $\mathrm{W}$ should be obtained. The solution process is as (4):

$$
P_{W}=\lambda w_{\max }
$$

Then finding a specific eigenvector $\mathrm{W}$, the normalized result of $\mathrm{W}$ is the weight allocation of each factor.

4) Consistency test.

After the weight distribution is obtained, the consistency test is also needed to judge whether the weight is reasonable. The consistency index needs to be calculated by (5).

$$
C I=\frac{\lambda_{\max }}{n-1}
$$

Among them, $\lambda_{\max }$ is the maximum eigenvalue of the judgment matrix

5) Consistency ratio (CR) was calculated by (6).

$$
\mathrm{CR}=\frac{C I}{R I}
$$

$\mathrm{RI}$ is a random consistency index, $\mathrm{RI}=\left[\begin{array}{llll}0 & 0 & 0.52 & 0.89\end{array}\right.$ $1.121 .261 .361 .411 .461 .491 .521 .54 \quad 1.561 .581 .59]$

If the level of consistency is not sufficient, decision makers should review the paired comparisons and make changes before implementing the AHP analysis.

\subsection{Calculation method of objective weight}

As an objective weighting method, entropy weight method mainly aims to determine the entropy value through the information entropy of each index[9].

\subsubsection{Construct index matrix}

The number of evaluation samples was $\mathrm{M}$; the evaluation index was $\mathrm{N}$, and each index value was $v_{i j}(i=$ $1,2, \ldots, m ; j=1,2, \ldots n)$; the index matrix is as (7):

$$
V=\left[\begin{array}{ccc}
v_{11} & \ldots & v_{1 n} \\
\ldots & \ldots & \ldots \\
v_{m 1} & \ldots & v_{m n}
\end{array}\right]
$$

\subsubsection{Normalized index matrix}

The normalized index matrix is obtained $\boldsymbol{X}=\left(x_{i j}\right)_{m n}$ can be calculated by (8):

$$
x_{i j}=v_{i j} /\left(\sum_{i=1}^{m}\left(v_{i j}\right)^{2}\right)^{1 / 2}
$$

In the expression, $x_{i j}$ Is the value of the $j_{\text {th }}$ index of the $i_{\text {th }}$ sample in the matrix. 


\subsubsection{Use entropy weight method to determine the index weight}

Index weight can be calculated by (9),(10) and (11):

$$
\begin{gathered}
h_{i j}=\left(1+x_{i j}\right) / \sum_{i=1}^{m}\left(1+x_{i j}\right) \\
k_{i}=\frac{1}{\ln m} \sum_{i=1}^{m} h_{i j} \ln h_{i j} \\
s_{j}=\left(1-k_{i}\right) / \sum_{j=1}^{n}\left(1-k_{i}\right)
\end{gathered}
$$

Among them, $\mathrm{H}_{\mathrm{ij}}$ is the occurrence probability of each indicator, $\mathrm{Ki}$ is the information entropy of the system, $\mathrm{S}_{\mathrm{j}}$ represents the entropy weight of the $j_{t h}$ index.

The index weight column vectors are as (12):

$$
S=\left(s_{1}, s_{2}, \ldots, s_{n}\right)^{T}
$$

Among them, $\mathrm{Sn}$ is the weight of the nth index.

\subsubsection{Weighting standardization}

The weighted standardization matrix is as (13):

$$
Y=\left(y_{i j}\right)_{m n}=\left(s_{j} x_{i j}\right)_{m n}
$$

$y_{i j}$ is the $j_{\text {th }}$ index value of the $i_{\text {th }}$ sample of the standardized matrix.

\subsection{Calculation method of combined weight}

In order to reflect the subjective nature of decisionmaking and the objectivity of decision-making in evaluation, it is necessary to integrate the results of the hierarchical analysis method and the empowerment of entropy method.

Based on the weighted results of the above analytic hierarchy process and entropy weight method, the weight vector calculated by the AHP is $T=\left\{t_{1}, t_{2}, \ldots, t_{n}\right\}$, the weight vector calculated by the entropy weight method is $S=\left\{s_{1}, s_{2}, \ldots, s_{n}\right\}$. Suppose the relative importance of the subjective weight vector to the combined weight is $\alpha$, the relative importance of objective weight vector to the combined weight is $\beta$, and it satisfies the minimum deviation between the combined weight vector $\mathrm{W}$ and the subjective weight vector $\mathrm{T}$, which can be described by (14) and (15).

$$
\begin{gathered}
\operatorname{minH}\left(w_{j}\right)=\alpha \times\left(w_{j}-t_{j}\right)^{2}+\beta \times\left(w_{j}-s_{j}\right)^{2} \\
\sum w_{j}=1,1 \leq j \leq n
\end{gathered}
$$

In this paper, the expected value of subjective weight and objective weight is the actual value of each index weight, namely $\mathrm{S}$. The relative important coefficients of the subjective and objective weight vectors of a single index can be calculated by using the subjective and objective weight actual values of each index, which can be calculated by (16):

$$
\left\{\begin{array}{l}
\alpha_{j}=\frac{t_{j}}{t_{j}+s_{j}} \\
\beta_{j}=\frac{s_{j}}{t_{j}+s_{j}}
\end{array}\right.
$$

For the evaluation index in the multi-decision matrix, the relative important coefficient of the overall subjective and objective weight vector can be calculated by (17):

$$
\left\{\begin{array}{l}
\alpha=\frac{\sum_{j=1}^{n} a_{j}}{\sum_{j=1}^{n} a_{j}+\sum_{j=1}^{n} \beta_{j}}=\frac{\sum_{j=1}^{n} \alpha_{j}}{n} \\
\beta=\frac{\sum_{j=1}^{n} \beta_{j}}{\sum_{j=1}^{n} a_{j}+\sum_{j=1}^{n} \beta_{j}}=\frac{\sum_{j=1}^{n} \beta_{j}}{n}
\end{array}\right.
$$

For each of the indices $\mathbf{x}_{\mathbf{j}}$, with $H\left(w_{j}\right)$ as the minimum of the optimal, which can be converted into (18):

$$
\left\{\begin{array}{l}
\min H=\left\{H\left(w_{1}\right), H\left(w_{2}\right), \ldots, H\left(w_{n}\right)\right\} \\
\text { s.t. } \sum_{j=1}^{n} w_{j}=1,0 \leq w_{j} \leq 1,1 \leq j \leq n
\end{array}\right.
$$

The multi-objective optimization model can be transformed into a single-objective optimization model for solution, which can be calculated by (19):

$$
\left\{\begin{aligned}
& \min H=\sum_{j=1}^{n}\left[a \times\left(w_{j}-t_{j}\right)^{2}\right] \\
&+\sum_{j=1}^{n}\left[\beta \times\left(w_{j}-s_{j}\right)^{2}\right] \\
& \text { s.t. } \sum_{j=1}^{n} w_{j}=1,0 \leq w_{j} \leq 1,1 \leq j \leq n
\end{aligned}\right.
$$

\section{Research on multi-dimensional energy efficiency assessment methods for regional integrated energy systems}

\subsection{Multi-dimensional energy efficiency assessment technology based on TOPSIS method}

The evaluation method is TOPSIS, which is an analysis method suitable for comparison and selection of multiple plans based on multiple indicators[10]. It can eliminate different indicators Dimensional influence, and can make full use of the information of the original data, so it can fully reflect the gap between the various programs, objectively reflect the actual situation, has the advantages of being true, intuitive and reliable, and it has no special requirements for sample data. Compared with the mutual analysis method of individual indicators, the TOPSIS method can collectively reflect the overall situation. The basic calculation process is as follows:

1) Multi-objective decision matrix construction

The scheme set of multi-index decision problem is set as $C=\left(C_{1}, C_{2}, \ldots, C_{m}\right)$, the index set is $M=$ $\left(M_{1}, M_{2}, \ldots, M_{n}\right)$, scheme $\mathrm{M}_{\mathrm{j}}$ versus index $\mathrm{Ci}$. The evaluation value is $r_{i j}(i=1,2, \ldots, n ; j=1,2, \ldots, m)$, the multi-objective decision matrix $\mathrm{R}$ can be obtained, as shown in (20).

$$
R=\left[\begin{array}{cccc}
r_{11} & r_{12} & \cdots & r_{1 m} \\
r_{21} & r_{21} & \cdots & r_{2 m} \\
\cdots & \cdots & \cdots & \cdots \\
r_{n 1} & r_{n 2} & \cdots & r_{n m}
\end{array}\right]
$$


2) Calculation of positive and negative ideal solutions

By the matrix $R=\left(r_{i j}\right)_{m \times n}$ and the weight vector $W=\left(w_{1}, w_{2}, \ldots, w_{m}\right)$. Multiply form a weighted decision matrix $Z=\left(Z_{i j}\right)_{m \times n}$. Calculate the positive ideal solution and negative ideal solution of the index, and get the positive ideal solution vector $Z+$ and negative ideal solution vector $Z-, Z^{+}=\left(Z_{1}^{+}, Z_{2}^{+}, \ldots, Z_{m}^{+}\right) . Z^{-}=$ $\left(Z_{1}^{-}, Z_{2}^{-}, \ldots, Z_{m}^{-}\right)$, as shown in (21) and (22).

$$
\begin{aligned}
z_{i}^{+} & =\max \left(z_{i 1}^{+}, z_{i 2}^{+}, \ldots, z_{i m}^{+}\right) \\
z_{i}^{-} & =\min \left(z_{i 1}^{-}, z_{i 2}^{-}, \ldots, z_{i m}^{-}\right)
\end{aligned}
$$

3) Calculation of relative distance

The distance from the positive ideal solution and the distance from the negative ideal solution can be calculated by (23) and (24).

$$
\begin{aligned}
& D_{j}^{+}=\sqrt{\sum_{i=1}^{m}\left(z_{i j}-z_{i}^{+}\right)^{2}} \\
& D_{j}^{-}=\sqrt{\sum_{i=1}^{m}\left(z_{i j}-z_{i}^{-}\right)^{2}}
\end{aligned}
$$

Among them, $i=1,2, \ldots, m ; j=1,2, \ldots, n$

4) Calculation of comprehensive evaluation value The comprehensive evaluation relative closeness degree of each evaluation object can be calculated by (25). The relative closeness degree represents the closeness degree of each program to the optimal program. The greater the relative closeness degree is, the more similar the program is to the optimal program, and the higher the ranking is.

$$
C_{j}=\frac{D_{j}^{-}}{D_{j}^{-}+D_{j}^{+}}, j=1,2, \ldots, n
$$

5) Ranking of evaluation results

According to the above formula, rank $C_{j}$ from the large to the small of the evaluation objects for the pros and cons of the order.

\subsection{Regional comprehensive energy multi- dimensional energy efficiency assessment process}

Combined with the above research content, the multidimensional energy efficiency assessment process of comprehensive energy is shown in the figure below.

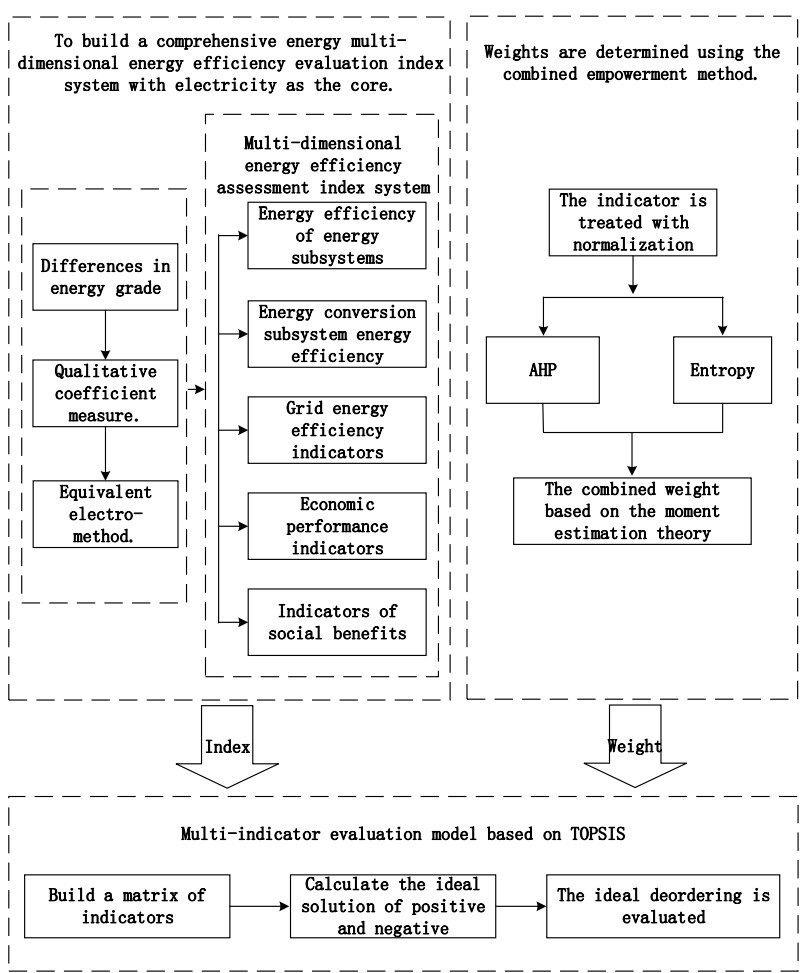

Fig2. Integrated energy multi-dimensional energy efficiency assessment process.

The evaluation process is as follows:

Firstly, from the energy efficiency, energy conversion efficiency, power efficiency, economic benefit and social benefit to construct comprehensive energy multidimensional evaluation index system, form a quantifiable indicators, combined with the technical specifications, standards, guidelines and give each index connotation and evaluation standard to calculate evaluation indexes.

Secondly, the combined weight method is used to calculate the weight of the index system. The subjective weight method is AHP. The objective weight method is entropy weight method. Various indicators were optimized by means of hierarchical clustering and expert intervention to obtain the final index weight.

Finally, based on the constructed index system and weight, TOPSIS method was used to evaluate the evaluation index, forming a multi-dimensional energy efficiency evaluation method for regional integrated energy system. The multi-dimensional energy efficiency of a integrated energy system was simulated and analyzed, and the evaluation results were obtained.

\section{Energy efficiency assessment and analysis of typical regional integrated energy systems}

\subsection{Calculation parameters of energy efficiency assessment}

A typical area consists of industrial production area and commercial area. In consideration of multi-energy complementary characteristics and renewable energy 
access, the electrical load demand of the area is supplied by external power grid and CCHP unit, the thermal load of the area is supplied by CCHP unit and electric boiler, and the cooling load of the area is supplied by conventional cooling machine, ground source heat pump, lithium bromide refrigerator and cold storage pool.

Taking into account the pollution-free emission conditions of renewable energy input in various energy technologies, all pollutant emissions from the operation of the final integrated energy system can be traced back to the production of electricity. The pollutant emission intensity is used to measure the pollutant emission per unit of power generation, as shown in the following table.

Table 3. Pollution emission intensity.

\begin{tabular}{|c|c|c|c|c|}
\hline $\begin{array}{c}\text { Power } \\
\text { generation } \\
\text { technology }\end{array}$ & SO2 & NOx & CO2 & CO \\
\hline $\begin{array}{c}\text { Gas power } \\
\text { generation }\end{array}$ & 0.000928 & 0.618 & 184.083 & 0.1702 \\
\hline A fuel cell & 0 & $<0.023$ & 635.04 & 0.0544 \\
\hline $\begin{array}{c}\text { Wind power } \\
\text { generation }\end{array}$ & 0 & 0 & 0 & 0 \\
\hline $\begin{array}{c}\text { Photovoltaic } \\
\text { power } \\
\text { generation }\end{array}$ & 0 & 00 & 0 & 0 \\
\hline
\end{tabular}

The regional land scale is 138.13 million square meters, and the construction area is estimated to be 227.92 million square kilometers according to the planning scheme. According to the general land use plan, all urban construction land within the planning scope, without basic farmland. Among them, the total area of the living area is 66.14 million square meters, the total area of the commercial area is 7.41 million square meters, and the total area of the industrial area is 61.49 million square meters based on $30 \%$ of the reserved land for unplanned projects.

Based on the heating load index and land use planning, the heating load, cooling load and domestic hot water load are simulated and estimated. The annual cumulative heating and cooling days are selected as 120 days. The specific results are as follows[11-12]:

Table 4. Calculation results of heating load of various buildings.

\begin{tabular}{|c|c|c|c|c|}
\hline Building type & $\begin{array}{c}\text { Construction } \\
\text { area (10000 } \\
\text { square meters) }\end{array}$ & $\begin{array}{c}\text { Design } \\
\text { heat load } \\
(\mathrm{kw})\end{array}$ & $\begin{array}{c}\text { Typical daily } \\
\text { cumulative } \\
\text { load (MWh / } \\
\mathrm{D})\end{array}$ & $\begin{array}{c}\text { Annual } \\
\text { cumulative } \\
\text { load } \\
(\mathrm{MWh} / \mathrm{a})\end{array}$ \\
\hline $\begin{array}{c}\text { Residence and } \\
\text { apartment }\end{array}$ & 56.70 & - & - & - \\
\hline Senior living garden & 8.39 & 3834 & 57.5 & 6902 \\
\hline business & 9.68 & 4704 & 70.6 & $846 \mathrm{~S}$ \\
\hline to work in an office & 6.07 & 3563 & 53.4 & 6413 \\
\hline school & 6.67 & 3915 & 58.7 & 7047 \\
\hline $\begin{array}{c}\text { Pharmaceutical R \& D } \\
\text { workshop }\end{array}$ & 61.49 & 39907 & 598.6 & 71833 \\
\hline $\begin{array}{c}\text { Pharmaceutical } \\
\text { intelligent } \\
\text { manufacturing } \\
\text { workshop }\end{array}$ & 31.84 & 20664 & 310.0 & 37195 \\
\hline total & 176.11 & 76588 & 1148.8 & 137859 \\
\hline
\end{tabular}

Table 5. Calculation results of cooling load for various buildings.

\begin{tabular}{|c|c|c|c|c|}
\hline Building type & $\begin{array}{c}\text { Construction } \\
\text { area (10000 } \\
\text { square } \\
\text { meters) }\end{array}$ & $\begin{array}{c}\text { Design } \\
\text { load } \\
(\mathrm{kw})\end{array}$ & $\begin{array}{c}\text { Typical daily } \\
\text { cumulative } \\
\text { load (MWh / } / \text { D) }\end{array}$ & $\begin{array}{c}\text { Annual } \\
\text { cumulative } \\
\text { load (MWh } \\
\text { / a) }\end{array}$ \\
\hline Residence and apartment & 56.70 & - & - & - \\
\hline Senior living garden & 8.39 & 8448 & 126.7 & 15207 \\
\hline business & 9.68 & 10899 & 163.5 & 19619 \\
\hline to work in an office & 6.07 & 5930 & 88.8 & 10675 \\
\hline Learning comparison & 6.67 & 7510 & 112.7 & 13518 \\
\hline $\begin{array}{c}\text { Pharmaceutical R \& D } \\
\text { workshop }\end{array}$ & 61.49 & 50857 & 762.8 & 91542 \\
\hline $\begin{array}{c}\text { Pharmaceutical } \\
\text { intelligent manufacturing } \\
\text { workshop }\end{array}$ & 31.84 & 28528 & 427.9 & 51351 \\
\hline total & 176.11 & 112174 & 1682.6 & 201914 \\
\hline
\end{tabular}

Table 6. Calculation results of domestic hot water load (heat) of various buildings.

\begin{tabular}{|c|c|c|c|c|}
\hline Building type & \begin{tabular}{|c|} 
Construction \\
area (10000 \\
square \\
meters) \\
\end{tabular} & $\begin{array}{l}\text { Design } \\
\text { load } \\
(\mathrm{kw})\end{array}$ & $\begin{array}{c}\text { Typical daily } \\
\text { cumulative load } \\
(\mathrm{MWh} / \mathrm{D})\end{array}$ & $\begin{array}{c}\text { Annual } \\
\text { cumulative } \\
\text { load } \\
(\mathrm{MWLI} / \mathrm{a})\end{array}$ \\
\hline $\begin{array}{l}\text { Residence and } \\
\text { apartment }\end{array}$ & 56.70 & - & - & - \\
\hline Senior living garden & 8.39 & 130.1 & 3.12 & 624.5 \\
\hline business & 9.68 & 23.4 & 0.56 & 112.5 \\
\hline to work in an office & 6.07 & 14.7 & 0.35 & 70.6 \\
\hline Learning comparison & 6.61 & 517.1 & 12.41 & 2482.4 \\
\hline $\begin{array}{c}\text { Pharmaceutical } \\
\text { research and } \\
\text { development } \\
\text { workshop }\end{array}$ & 61.49 & - & - & - \\
\hline $\begin{array}{c}\text { Pharmaceutical } \\
\text { intelligent } \\
\text { manufacturing } \\
\text { workshop }\end{array}$ & 31.84 & - & - & - \\
\hline total & 176.11 & 685.4 & 16.5 & 3290.1 \\
\hline
\end{tabular}

Considering the multi energy complementary characteristics and renewable energy access, the electric load demand of the park is supplied by the external power grid and CCHP units, the thermal load of the park is supplied by CCHP units and electric boilers, and the cooling load of the park is supplied by conventional chillers, ground source heat pumps, lithium bromide chillers and cold water storage tanks. Among them, ground source heat pump can be used to cool underground water by electricity in summer. The cop-c of the equipment varies with the temperature of underground cooling water.

\subsection{Efficiency assessment of system energy}

In the multi-dimensional energy efficiency assessment of this chapter, typical areas are selected for multidimensional energy efficiency assessment.

When the regional integrated energy system is in the source grid load storage configuration, the optimal capacity allocation can ensure that the system can achieve the lowest cost investment under the conditions of meeting the reliability and security constraints, and ensure that the system operates in the optimal situation. Excessive capacity allocation of system equipment will increase the cost of the system, but insufficient configuration will lead to the waste of renewable energy and the shortage of energy supply. Therefore, in order to 
compare and analyze the multi-dimensional energy efficiency of the system under different configuration modes, this chapter selects two different schemes of single objective optimal configuration mode and multiobjective optimal configuration mode of regional comprehensive energy system for multi-dimensional energy efficiency evaluation.

\subsubsection{Overall energy efficiency assessment of areas}

The different capacity configuration schemes are as follows:

1) Single objective optimal energy supply mode

Under the optimal mode of environmental benefits, the capacity allocation is carried out to reduce carbon emissions and pollutant emissions. The capacity of typical areas is as follows: photovoltaic power generation system $10000 \mathrm{~kW}$, gas turbine $117630 \mathrm{kw}$, absorption chiller $70578 \mathrm{kw}$, waste heat boiler $56462 \mathrm{kw}$, gas boiler $24527 \mathrm{kw}$, electric refrigerator $10534 \mathrm{kw}$, and other energy is provided by the grid.

2) Multi objective optimal energy supply mode

Under the multi-objective benefit optimal energy supply mode, the appropriate distributed energy equipment is selected for the typical regional resource situation, and the capacity allocation is carried out with the minimum annual cost as the goal. The configuration capacity is as follows: photovoltaic power generation system $10000 \mathrm{~kW}$, gas turbine $59627 \mathrm{kw}$, absorption chiller $35776 \mathrm{kw}$, residual heat boiler $28620 \mathrm{kw}$, gas-fired boiler $50078 \mathrm{kw}$, electric refrigerator $25327 \mathrm{kw}$, and the rest energy is provided by the grid.

According to the calculation method of indexes, the results are as follows:

Table 7. Indexes and calculation results of different energy supply modes in typical areas.

\begin{tabular}{|c|c|c|c|}
\hline $\begin{array}{c}\text { Serial } \\
\text { number }\end{array}$ & Secondary indicators & $\begin{array}{c}\text { The single } \\
\text { objective } \\
\text { benefit is the } \\
\text { best }\end{array}$ & \begin{tabular}{|c|} 
Multi \\
objective \\
benefit \\
optimization \\
\end{tabular} \\
\hline 1 & $\begin{array}{l}\text { Power supply } \\
\text { efficiency }\end{array}$ & 0.95 & 0.96 \\
\hline 2 & $\begin{array}{l}\text { Efficiency of cooling } \\
\text { and heating network }\end{array}$ & 0.95 & 0.96 \\
\hline 3 & Gas supply efficiency & 0.94 & 0.96 \\
\hline 4 & $\begin{array}{c}\text { Power system } \\
\text { efficiency }\end{array}$ & 0.97 & 0.97 \\
\hline 5 & $\begin{array}{c}\text { Conversion efficiency } \\
\text { of electric to hot / cold } \\
\text { energy }\end{array}$ & 3.5 & 4.7 \\
\hline 6 & $\begin{array}{c}\text { Conversion efficiency } \\
\text { of gas to electricity / } \\
\text { thermal energy }\end{array}$ & 0 & 2.1 \\
\hline 7 & $\begin{array}{l}\text { Conversion efficiency } \\
\text { of hot to cold energy }\end{array}$ & 1.1 & 2.5 \\
\hline 8 & $\begin{array}{l}\text { Power supply } \\
\text { reliability }\end{array}$ & $99.9815 \%$ & $99.9832 \%$ \\
\hline 9 & $\begin{array}{c}\text { Qualified rate of outlet } \\
\text { pressure of gas } \\
\text { pipeline network }\end{array}$ & $99.5 \%$ & $99.5 \%$ \\
\hline 10 & \begin{tabular}{|l|} 
Failure rate of cooling \\
and heating equipment
\end{tabular} & $1.1 \%$ & $0.2 \%$ \\
\hline
\end{tabular}

\begin{tabular}{|c|c|c|c|}
\hline 11 & $\begin{array}{c}\text { Pass rate of harmonic } \\
\text { content in medium and } \\
\text { low pressure platform } \\
\text { area }\end{array}$ & $95 \%$ & $96 \%$ \\
\hline 12 & $\begin{array}{l}\text { Voltage combination } \\
\text { rate of medium and } \\
\text { low voltage platform } \\
\text { area }\end{array}$ & $99.9872 \%$ & $99.9882 \%$ \\
\hline 13 & $\begin{array}{l}\text { Qualified rate of } \\
\text { export natural gas }\end{array}$ & $100 \%$ & $100 \%$ \\
\hline 14 & $\begin{array}{c}\text { Pass rate of cold and } \\
\text { hot outlet temperature } \\
\text { fluctuation }\end{array}$ & $98 \%$ & $99 \%$ \\
\hline 15 & Unit energy cost & $1.1 \mathrm{kWh} /$ yuan & $\begin{array}{l}0.97 \mathrm{kWh} / \\
\text { yuan }\end{array}$ \\
\hline 16 & $\begin{array}{c}\text { Unit investment to } \\
\text { increase energy supply }\end{array}$ & $\begin{array}{c}2.4 \mathrm{kWh} / \text { million } \\
\text { yuan }\end{array}$ & $\begin{array}{c}2.1 \\
\mathrm{kWh} / \mathrm{million} \\
\text { yuan }\end{array}$ \\
\hline 17 & $\begin{array}{c}\text { Unit investment } \\
\text { reduces shutdown time }\end{array}$ & $20 \mathrm{~h}$ & $31 \mathrm{~h}$ \\
\hline 18 & $\begin{array}{l}\text { Financial net present } \\
\text { value }\end{array}$ & 30880000yuan & 37230000yuan \\
\hline 19 & Payback period & 12.3year & 9.2year \\
\hline 20 & $\begin{array}{c}\text { Financial internal rate } \\
\text { of return }\end{array}$ & $10.33 \%$ & $16.7 \%$ \\
\hline 21 & $\begin{array}{c}\text { Renewable energy } \\
\text { consumption rate }\end{array}$ & $89 \%$ & $97 \%$ \\
\hline 22 & $\begin{array}{l}\text { Proportion of } \\
\text { renewable energy } \\
\text { production capacity }\end{array}$ & $37 \%$ & $54 \%$ \\
\hline 23 & $\begin{array}{c}\text { Annual carbon dioxide } \\
\text { emission reduction }\end{array}$ & $14.62 \mathrm{t}$ & $17.42 \mathrm{t}$ \\
\hline 24 & $\begin{array}{c}\text { Annual sulfur dioxide } \\
\text { emission reduction }\end{array}$ & $0.05 \mathrm{t}$ & $0.06 \mathrm{t}$ \\
\hline
\end{tabular}

The subjective weights of the first and second level indexes are calculated by analytic hierarchy process (AHP), and the objective weights of each secondary index are calculated by entropy weight method. Then, based on the idea of moment estimation, the objective function of combined weights is constructed, and the optimal combination weights are obtained by solving nonlinear programming.

Table 8. Calculation results of index combination weight under multi-objective benefit optimal energy supply mode.

\begin{tabular}{|c|c|c|c|c|}
\hline $\begin{array}{c}\text { Serial } \\
\text { number }\end{array}$ & Secondary indicators & $\begin{array}{c}\text { Subjective } \\
\text { weight }\end{array}$ & $\begin{array}{c}\text { Objective } \\
\text { weight }\end{array}$ & $\begin{array}{c}\text { Combination } \\
\text { weight }\end{array}$ \\
\hline 1 & $\begin{array}{c}\text { Power supply } \\
\text { efficiency }\end{array}$ & 0.0716 & 0.0001 & 0.0573 \\
\hline 2 & $\begin{array}{c}\text { Efficiency of cooling } \\
\text { and heating network }\end{array}$ & 0.0779 & 0.0001 & 0.0623 \\
\hline 3 & Gas supply efficiency & 0.0296 & 0.0002 & 0.0237 \\
\hline 4 & $\begin{array}{c}\text { Power system } \\
\text { efficiency }\end{array}$ & 0.0322 & 0.0031 & 0.0258 \\
\hline 5 & $\begin{array}{c}\text { Conversion } \\
\text { efficiency of electric } \\
\text { to hot / cold energy }\end{array}$ & 0.0440 & 0.0377 & 0.0427 \\
\hline 6 & $\begin{array}{c}\text { Conversion } \\
\text { efficiency of gas to } \\
\text { electricity / thermal } \\
\text { energy }\end{array}$ & 0.0638 & 0.0008 & 0.0512 \\
\hline 7 & $\begin{array}{c}\text { Conversion } \\
\text { efficiency of hot to } \\
\text { cold energy }\end{array}$ & 0.0279 & 0.2722 & 0.0768 \\
\hline
\end{tabular}




\begin{tabular}{|c|c|c|c|c|}
\hline 8 & $\begin{array}{l}\text { Power supply } \\
\text { reliability }\end{array}$ & 0.0701 & 0.0010 & 0.0561 \\
\hline 9 & \begin{tabular}{|c|} 
Qualified rate of \\
outlet pressure of gas \\
pipeline network
\end{tabular} & 0.0227 & 0.0004 & 0.0182 \\
\hline 10 & $\begin{array}{c}\text { Failure rate of } \\
\text { cooling and heating } \\
\text { equipment }\end{array}$ & 0.0315 & 0.1986 & 0.0649 \\
\hline 11 & $\begin{array}{c}\text { Pass rate of harmonic } \\
\text { content in medium } \\
\text { and low pressure } \\
\text { platform area }\end{array}$ & 0.0521 & 0.0005 & 0.0417 \\
\hline 12 & $\begin{array}{c}\text { Voltage combination } \\
\text { rate of medium and } \\
\text { low voltage platform } \\
\text { area }\end{array}$ & 0.0604 & 0.0009 & 0.0483 \\
\hline 13 & $\begin{array}{l}\text { Qualified rate of } \\
\text { export natural gas }\end{array}$ & 0.0223 & 0.0004 & 0.0178 \\
\hline 14 & \begin{tabular}{|c|} 
Pass rate of cold and \\
hot outlet \\
temperature \\
fluctuation \\
\end{tabular} & 0.0310 & 0.0001 & 0.0248 \\
\hline 15 & Unit energy cost & 0.0334 & 0.0069 & 0.0281 \\
\hline 16 & $\begin{array}{c}\text { Unit investment to } \\
\text { increase energy } \\
\text { supply }\end{array}$ & 0.0475 & 0.0078 & 0.0396 \\
\hline 17 & $\begin{array}{l}\text { Unit investment } \\
\text { reduces shutdown } \\
\text { time }\end{array}$ & 0.0482 & 0.0195 & 0.0425 \\
\hline 18 & $\begin{array}{c}\text { Financial net present } \\
\text { value }\end{array}$ & 0.0350 & 0.2076 & 0.0695 \\
\hline 19 & Payback period & 0.0381 & 0.0366 & 0.0378 \\
\hline 20 & $\begin{array}{c}\text { Financial internal rate } \\
\text { of return }\end{array}$ & 0.0236 & 0.1192 & 0.0427 \\
\hline 21 & $\begin{array}{l}\text { Renewable energy } \\
\text { consumption rate }\end{array}$ & 0.0497 & 0.0032 & 0.0404 \\
\hline 22 & $\begin{array}{c}\text { Proportion of } \\
\text { renewable energy } \\
\text { production capacity }\end{array}$ & 0.0455 & 0.0615 & 0.0487 \\
\hline 23 & $\begin{array}{l}\text { Annual carbon } \\
\text { dioxide emission } \\
\text { reduction }\end{array}$ & 0.0260 & 0.0134 & 0.0235 \\
\hline 24 & $\begin{array}{c}\text { Annual sulfur dioxide } \\
\text { emission reduction }\end{array}$ & 0.0158 & 0.0145 & 0.0155 \\
\hline
\end{tabular}

The TOPSIS evaluation method is used to evaluate the energy efficiency of two energy supply modes in each typical scenario.

Through the simulation, the energy efficiency evaluation results of different energy supply modes in typical regions are as follows.

Table 9. Calculation results of typical regional energy efficiency assessment.

\begin{tabular}{|c|c|c|}
\hline $\begin{array}{c}\text { Energy supply } \\
\text { mode }\end{array}$ & $\begin{array}{c}\text { The single objective } \\
\text { benefit is the best }\end{array}$ & $\begin{array}{c}\text { Multi objective } \\
\text { benefit optimization }\end{array}$ \\
\hline score & 0.79612 & 0.90367 \\
\hline
\end{tabular}

Through the evaluation of multi-dimensional energy efficiency under two kinds of energy supply modes in typical areas, the results are shown in the table above. Through the evaluation, it is found that the energy efficiency of the energy supply mode with multi-objective benefit is better than that under the mode of environmental single objective benefit optimization.

\section{Summary}

The evaluation of integrated energy systems at the regional level has helped to form a closed loop in the planning of integrated energy systems at the regional level and guide the planning of integrated energy systems better. This paper studies the evaluation index system of regional-level integrated energy system, puts forward the multi-dimensional energy efficiency evaluation method, assists the better planning and operation of the integrated energy system, gives full play to the advantages of the system in the coordination of various energy technologies, reduces the cost of multi-energy coupling, and improves the comprehensive energy efficiency.

\section{References}

1. GUO Yanfei, REN Xuegui,JU Li, JIANG Shiyao. The comprehensive efficiency evaluation method for integrated energy system based on AHP[J]. JOURNAL OF EIECTRIC POWER SCIENCE AND TECHNOLOGY, 2018, 33(04):121-128.

2. LU Shuowei. Research on planning design and smart Control Optimization of Integrated Energy System [D].ZHEJIANG UNIVERSITY,2019.

3. Willem H, Lin Y, Lekov A. Review of energy efficiency and system performance of residential heat pump water heaters[J]. Energy Buld, 2017; 143(5):191-201.

4. Wang J J, Yang K, Xu ZL, et al. Energy and exergy analyses of an integrated CCHP system with biomass air gasification[J]. Applied Energy,2015(5):317-27.

5. LIU Xiaoou, GE Shaoyun. Definition and Correlation Analysis on Energy Utilization Efficiency of Regional Integrated Energy system [J]. Automation of Electric Power Systems, 2020,44(08):8-19.

6. LIU Hong, ZHAO Yue, LIU Xiaoou, ZHANG Qiang, GE Shaoyun, LIU Jingy. Comprehensive Energy Efficiency Assessment of Park-level Multi-energy System Considering the Difference of Energy grade [J]. Power System Technology, 2019,43(08):28352843.

7. CHEN Wei, XIA Jianhua. An Optimal Weights Combination Method Considering both Subiective and obiective Weight Information [J]. MATHEMATICS IN PRACTICE AND THEORY ,2007(01):17-22.

8. Manoj Mathew, Ripon K. Chakrabortty, Michael J. Ryan, A novel approach integrating AHP and TOPSIS under spherical fuzzy sets for advanced manufacturing system selection[J], Engineering Applications of Artificial Intelligence, Volume 96,2020,103988.

9. Zhiqiang Geng, Fenfen Liu, Dirui Shang, Yongming Han, Ying Shang, Chong Chu. Early warning and control of food safety risk using an improved AHCRBF neural network integrating AHP-EW[J]. Journal of Food Engineering, Volume 292,2021,110239. 
10. S. Bathrinath, R.K.A. Bhalaji, S. Saravanasankar, Risk analysis in textile industries using AHPTOPSIS[J]. Materials Today: Proceedings,2020.

11. HUANG Wentao, WANG Xiaobo, TAI Nengling, DAI Shigang, CHEN Zhenyu, YANG Bin. The energy Coupling Conversion Model and Cascade Utilization Method for Microgrid with Heat and Power System[J/OL]. Proceedings of the CSEE,: 110 [2020-07-28]. http://kns.cnki.net/kcms/detail/11.2107.TM.2020033 0.1451.016.html.

12. Wang Li, Wu renbo, Pan Kaiyan, Wang Yuqin, Wang liye. Research on the construction of intelligent integrated energy management and operation center in the park [J]. Electrical Engineering, 2019,20(08):110-114+130. 